\title{
Luaran Bayi Kurang Bulan Late Preterm
}

\author{
I Wayan Dharma Artana \\ Bagian Ilmu Kesehatan Anak Fakultas Kedokteran Universitas Udayana RSUP Sanglah, Denpasar
}

Latar belakang. Bayi kurang bulan (BKB) mempunyai risiko tinggi terhadap penyakit-penyakit yang berhubungan dengan prematuritas. Kejadian BKB late preterm adalah $75 \%$ dari kelahiran BKB.

Tujuan. Mengetahui dan membandingkan luaran lama rawat, kesakitan dan kematian BKB late preterm dengan bayi cukup bulan (BCB).

Metode. Penelitian kohort prospektif, subyek faktor risiko adalah BKB late preterm dan BCB sebagai kontrol, yang lahir di RSUP Sanglah Denpasar mulai Januari 2010 sampai Desember 2010. Perhitungan analisis untuk mencari hubungan antara faktor risiko BKB late preterm dengan lama rawat, kejadian kesakitan dan kematian, dilakukan analisis multivariat dengan regresi logistik dan chi square.

Hasil. Didapatkan perbedaan bermakna di antara kedua kelompok mengenai lama rawat <3 hari $(p=0,027$; $\mathrm{RR}=2,76$; IK 95\%,12-6,15), kesakitan $(p=0,016$; RR=3,84; IK 95\% 2,06-8,49) kematian $(p=0,001$; $\mathrm{RR}=6,6$; IK $95 \%$ 1,46-9,37).

Kesimpulan. Bayi kurang bulan late preterm memiliki risiko lebih tinggi menjalani waktu perawatan di rumah sakit, kejadian kesakitan, dan kematian dibandingkan BCB. Sari Pediatri 2012;14(1):62-66.

Kata kunci: bayi kurang bulan late preterm, luaran, faktor risiko

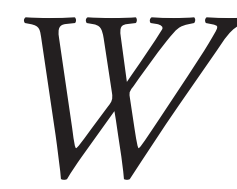

orld Health Organization (WHO) mencatat selama periode pertengahan 1990-an hingga tahun 2007 terdapat sekitar 130 juta lahir bayi kurang bulan (BKB) atau dengan rasio setiap 10 kelahiran bayi ada 1 bayi yang lahir BKB. Dilaporkan $85 \%$ BKB terjadi

\footnotetext{
Alamat korespondensi:

Dr. I Wayan Dharma Artana, Sp.A, Bagian Ilmu Kesehatan Anak, Fakultas Kedokteran Universitas Udayana, RSUP Sanglah Denpasar. Jl. Pulau Nias 80114. Telp/Fax. (0361) 244038 atau (0361) 257387,

E-mail:dharma.artana@yahoo.co.id
}

di negara-negara miskin terutama Asia. ${ }^{1}$ Beberapa tahun terakhir $\mathrm{BKB}$ yang lahir dengan usia kehamilan 34 minggu sampai dengan $<37$ minggu, (BKB late preterm), memberikan kontribusi lebih dari $75 \%$ kelahiran BKB. ${ }^{2}$ Kelahiran dengan usia kehamilan $<37$ minggu mempunyai risiko tinggi terhadap berbagai penyakit yang berhubungan dengan prematuritas. ${ }^{3}$ Data luaran lama rawat, kesakitan, dan kematian BKB late preterm di Indonesia masih terbatas. Penelitian dilakukan untuk mengetahui dan membandingkan luaran lama rawat, kesakitan, dan kematian pada BKB late preterm dengan $\mathrm{BCB}$ yang lahir di ruang bersalin RSUP Sanglah Denpasar. 


\section{Metode}

Penelitian kohort prospektif, subyek adalah neonatus dengan faktor risiko BKB late preterm dan kelompok tanpa faktor risiko BCB yang lahir di ruang bersalin RSUP Sanglah Denpasar. Subyek penelitian dinilai terhadap lama rawat, kesakitan, dan kematian. Data diambil dari catatan medis subyek saat di ruang perawatan gabung ibu-bayi atau di NICU (Neonatal Intensive Care Unit) RSUP Sanglah Denpasar. Tempat penelitian adalah ruang bersalin, NICU dan ruang perawatan gabung ibu dan bayi RSUP Sanglah Denpasar, dimulai bulan Januari 2010 sampai Desember 2010. Subyek dipilih dengan cara non random sampling yaitu consecutive sampling. Subyek yang dipilih adalah semua subyek yang memenuhi kriteria inklusi yaitu bayi yang lahir di ruang bersalin RSUP Sanglah Denpasar, usia kehamilan 34-41 minggu berdasarkan HPHT (hari pertama haid terakhir) ibu serta sesuai dengan perhitungan new ballard score dan setuju ikut serta dalam penelitian setelah diberikan penjelasan dan menandatangani informed consent. Subyek tidak diikutsertakan dalam penelitian apabila terdapat kelainan kongenital mayor, riwayat ibu dengan imunodefisiensi, tidak didapatkan keterangan HPHT ibu. Penilaian dan keterangan kelaikan etik penelitian ini diberikan oleh Komisi Etika Penelitian Fakultas Kedokteran Universitas Udayana/ RSUP Sanglah, Denpasar.

Bayi cukup bulan (BCB) adalah bayi lahir dengan usia kehamilan ibu 37 sampai dengan 41 minggu berdasarkan HPHT ibu dan dipastikan dengan penilaian new ballard score. Bayi kurang bulan (BKB) late preterm adalah bayi lahir dengan usia kehamilan ibu 34 sampai dengan <37 minggu berdasarkan HPHT ibu dan dipastikan dengan penilaian new ballard score. ${ }^{2}$ Hari pertama haid terakhir (HPHT) didapatkan dari anamnesis atau catatan buku kehamilan. Lama rawat adalah waktu yang dibutuhkan untuk penanganan dan perawatan bayi sesuai dengan standar pelayanan yang ada di RSUP Sanglah Denpasar. Data dikumpulkan berupa HPHT ibu, nama bayi, nomer rekam medis, jenis kelamin, umur, diagnosis, lama rawat, dan kematian. Perhitungan analisis untuk mencari hubungan antara faktor risiko BKB late preterm dengan lama rawat, kejadian kesakitan dan kematian, dilakukan analisis multivariat dengan regresi logistik dan chi square. Analisis data dilakukan dengan bantuan komputer dengan menggunakan software statistik.

\section{Hasil}

Selama periode penelitian didapatkan 1468 kelahiran bayi dan 1344 eligible subyek neonatus yang lahir diruang bersalin RSUP Sanglah Denpasar, 179 dieksklusi karena 146 subyek tanpa diketahui HPHT, 25 orang tua bayi menolak ikut serta dalam penelitian, 6 subyek dengan kelainan kongenital mayor dan 2 subyek dengan riwayat ibu dengan imunodefisiensi. Didapatkan 1165 subyek turut serta dalam penelitian, 87 dari total 98 subyek BKB late preterm dan 1078 subyek BCB, seperti tertera pada Gambar 1. Proporsi $\mathrm{BKB}$ late preterm dari total 1468 kelahiran di RSUP Sanglah Denpasar 6,67\%. Total 98 subyek BKB late preterm merupakan kontributor $71 \%$ kelahiran $\mathrm{BKB}$ $<37$ minggu (138 BKB).

Dari total subyek kelompok BKB late preterm 87 subyek, 41 (47\%) laki-laki dan 46 (53\%) perempuan, sedangkan pada kelompok tanpa faktor risiko 495 (46\%) laki-laki dan 581 (54\%) perempuan. Metode persalinan 12,6\% dengan section cesaria pada kelompok $\mathrm{BKB}$ late preterm dan $11 \%$ pada BCB. Riwayat persalinan kurang bulan sebelumnya $10,3 \%$ pada kelompok BKB late preterm dan 3,4\% pada kelompok BCB. Paritas ibu $\leq 2$ kali $65,5 \%$ dan $>2$ kali $34,5 \%$ pada kelompok BKB late preterm dan $60,9 \%$ serta $39,1 \%$ pada kelompok BCB. Usia ibu $<20$ tahun $28,7 \%, 20-35$ tahun 50,5\% dan ibu dengan usia $>35$ tahun 20,8\% pada kelompok BKB late preterm dan $15,2 \%, 81,1 \%$ serta 3,7\% pada kelompok BCB. Rerata lama rawat subyek kelompok BKB late preterm

1468 kelahiran bayi

di ruang persalinan RSUP

Sanglah Denpasar

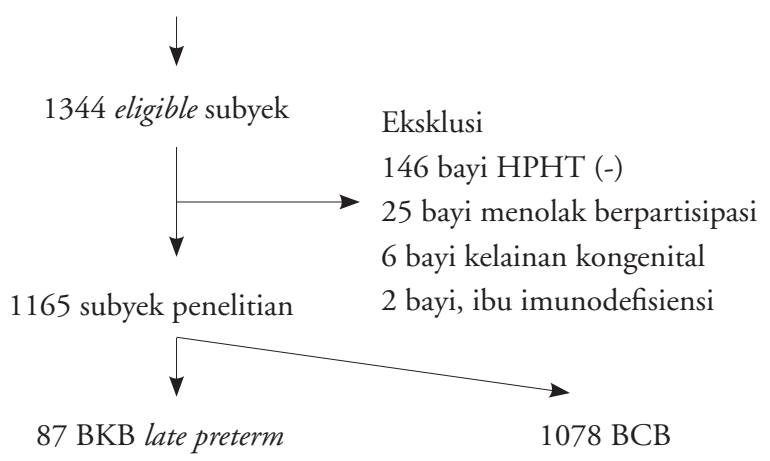

Gambar 1. Jumlah subyek penelitian 
6,2 hari sedangkan pada kelompok BCB 3,8 hari. Perawatan NICU sebesar 8\% pada subyek kelompok $\mathrm{BKB}$ late preterm sedangkan pada kelompok $\mathrm{BCB}$ $1,2 \%$. Ventilasi mekanik yang diperlukan selama perawatan pada subyek kelompok BKB late preterm ventilator $2,3 \%$ dan continuous positive airway pressure $8 \%$ sedangkan pada kelompok BCB 0,8\% dan 1,9\%. Luaran kejadian asfiksia pada kelompok BKB late preterm 6,9\%, respirasi distress $9,2 \%$, hipotermi $2,3 \%$, hipoglikemi 6,9\%, hiperbilirubinemia 5,7\%, dan sepsis $5,7 \%$ sedangkan pada kelompok BCB asfiksia 1,7\%, respirasi distress $1,8 \%$, hipotermi $0,6 \%$, hipoglikemi $1,2 \%$, hiperbilirubinemia $1,4 \%$ dan sepsis $1,7 \%$. Luaran kematian $<48$ jam 3,4\%, 2-7 hari 2,3\% dan $>7-28$ hari 2,3\% pada kelompok $\mathrm{BKB}$ late preterm sedangkan pada kelompok BCB luaran kematian $<48$ jam 0,5\%, 2-7 hari 0,3\% dan $>7-28$ hari $0,4 \%$ (Tabel 1).

Analisis proporsi luaran perinatal lama perawatan, kesakitan, dan kematian pada kedua kelompok dibandingkan secara statistik. Didapatkan perbedaan bermakna di antara kedua kelompok pada lama rawat $<3$ hari ( $p=0,027$; $\mathrm{RR}=2,76$; IK95\% 1,12-6,15), untuk kejadian kesakitan $(p=0,016 ; \mathrm{RR}=3,84$; IK95\% 2,06$8,49)$ dan untuk perbandingan kematian pada kedua kelompok $(p=0,001 ; \mathrm{RR}=6,6$; IK95\% 1,46-9,37), secara lengkap tertera pada Tabel 2.

Luaran kejadian kesakitan secara spesifik seperti asfiksia, respirasi distress, hipotermi, hipoglikemi, hiperbilirubinemia, dan sepsis didapatkan perbedaan kejadian pada kedua kelompok (Tabel 3). Terdapat perbedaan bermakna di antara kedua kelompok pada kejadian asfiksia $(\mathrm{RR}=3,72 ; \mathrm{IK} 95 \% 1,22-6,99)$, respirasi distress ( $\mathrm{RR}=4,48$; IK95\% 1,44-7,70), hipotermi $(\mathrm{RR}=3,35$; IK95\% 1,02-8,26), hipoglikemi $(\mathrm{RR}=3,87$; IK95\% 1,31-7,49), hiperbilirubinemia $(\mathrm{RR}=2,91$; IK $95 \%$ 1,13-5,66) dan kejadian sepsis ( $\mathrm{RR}=2,24$; IK95\% $1,35-6,28)$. Luaran perinatal kematian pada kedua
Tabel 1. Karakteristik populasi penelitian

\begin{tabular}{|c|c|c|}
\hline Variabel & $\begin{array}{c}\mathrm{BKB} \\
\text { late preterm }\end{array}$ & $\mathrm{BCB}$ \\
\hline \multicolumn{3}{|l|}{ Jenis kelamin, n (\%) } \\
\hline Laki-laki & $41(47,0)$ & $495(46,0)$ \\
\hline Perempuan & $46(53,0)$ & $581(54,0)$ \\
\hline \multicolumn{3}{|l|}{ Metode persalinan, n (\%) } \\
\hline Sectio cesaria & $11(12,6)$ & $119(11,0)$ \\
\hline Normal pervaginan & $75(86,2)$ & $940(87,4)$ \\
\hline Vacuum/forceps & $1(1,2)$ & $17(1,6)$ \\
\hline \multicolumn{3}{|l|}{ Riwayat persalinan, n (\%) } \\
\hline Prematur & $9(10,3)$ & $37(3,4)$ \\
\hline \multicolumn{3}{|l|}{ Paritas (kali), n (\%) } \\
\hline$\leq 2$ & $57(65,5)$ & $656(60,9)$ \\
\hline$>2$ & $30(34,5)$ & $420(39,1)$ \\
\hline \multicolumn{3}{|l|}{ Usia ibu (tahun), n (\%) } \\
\hline$<20$ & $25(28,7)$ & $164(15,2)$ \\
\hline $20-35$ & $44(50,5)$ & $873(81,1)$ \\
\hline$\geq 35$ & $18(20,8)$ & $39(3,7)$ \\
\hline \multicolumn{3}{|l|}{ Lama rawat, hari } \\
\hline Rerata (SB) & $6,2(1,1)$ & $3,8(1,4)$ \\
\hline \multicolumn{3}{|l|}{ Kesakitan, n (\%) } \\
\hline Asfiksia & $6(6,9)$ & $18(1,7)$ \\
\hline Respirasi distres & $8(9,2)$ & $19(1,8)$ \\
\hline Hipotermi & $2(2,3)$ & $7(0,6)$ \\
\hline Hipoglikemi & $6(6,9)$ & $14(1,2)$ \\
\hline Hiperbilirubinemia & $5(5,7)$ & $15(1,4)$ \\
\hline Sepsis & $5(5,7)$ & $18(1,7)$ \\
\hline \multicolumn{3}{|l|}{ Tempat perawatan, n (\%) } \\
\hline NICU & $7(8,0)$ & $14(1,2)$ \\
\hline \multicolumn{3}{|l|}{ Ventilasi mekanik, n (\%) } \\
\hline Ventilator & $2(2,3)$ & $9(0,8)$ \\
\hline СРAP & $7(8,0)$ & $21(1,9)$ \\
\hline \multicolumn{3}{|l|}{ Kematian (hari), n (\%) } \\
\hline$<2$ & $3(3,4)$ & $5(0,5)$ \\
\hline $2-7$ & $2(2,3)$ & $3(0,3)$ \\
\hline$>7-28$ & $2(2,3)$ & $4(0,4)$ \\
\hline
\end{tabular}

$\mathrm{BKB}=$ Bayi kurang bulan, $\mathrm{BCB}=$ Bayi cukup bulan

Tabel 2. Luaran kelompok BKB late preterm dan BCB

\begin{tabular}{ccccc}
\hline \multirow{2}{*}{ Variabel } & \multicolumn{2}{c}{ Proporsi (\%) } & $p$ & Risiko relatif (IK 95\%) \\
\cline { 2 - 3 } & $\begin{array}{c}\text { Bayi kurang bulan late } \\
\text { preterm }\end{array}$ & Bayi cukup bulan & & \\
\hline Lama rawat $<3$ hari & 28,2 & 88,7 & 0,027 & $2,76(1,12-6,15)$ \\
Kesakitan & 36,7 & 8,4 & 0,016 & $3,84(2,06-8,49)$ \\
Kematian & 8,0 & 1,1 & 0,001 & $6,6(1,46-9,37)$ \\
\hline
\end{tabular}

IK: Interval kepercayaan; $p$ : probabilitas; RR: Risiko relatif 
I Wayan Dharma Artana dkk: Luaran bayi kurang bulan late preterm

Tabel 3. Sub-analisis luaran kesakitan dan kematian pada kelompok BKB late preterm dan BCB

\begin{tabular}{|c|c|c|c|c|}
\hline \multirow{2}{*}{ Variabel } & \multicolumn{2}{|c|}{ Proporsi (\%) } & \multirow{2}{*}{$\mathrm{RR}$} & \multirow{2}{*}{ IK 95\% } \\
\hline & BKB late preterm & $\mathrm{BCB}$ & & \\
\hline \multicolumn{5}{|l|}{ Kesakitan } \\
\hline Asfiksia & 6,9 & 1,7 & 3,72 & $1,22-6,99$ \\
\hline Respirasi distress & 9,2 & 1,8 & 4,48 & $1,44-7,70$ \\
\hline Hipotermi & 2,3 & 0,6 & 3,35 & $1,02-8,26$ \\
\hline Hipoglikemi & 6,9 & 1,2 & 3,87 & $1,31-7,49$ \\
\hline Hiperbilirubinemia & 5,7 & 1,4 & 2,91 & $1,13-5,66$ \\
\hline Sepsis & 5,7 & 1,7 & 2,24 & $1,35-6,28$ \\
\hline \multicolumn{5}{|l|}{ Kematian (hari) } \\
\hline$<2$ & 3,4 & 0,5 & 5,88 & $1,49-10,52$ \\
\hline $2-7$ & 2,3 & 0,3 & 6,11 & $2,06-12,74$ \\
\hline$>7-28$ & 2,3 & 0,4 & 5,59 & $1,93-8,89$ \\
\hline
\end{tabular}

IK: Interval kepercayaan; RR: Risiko relatif

kelompok juga dibandingkan, didapatkan perbedaan kejadian kematian pada kedua kelompok. Terdapat perbedaan bermakna di antara kedua kelompok pada kejadian kematian $<2$ hari ( $\mathrm{RR}=5,88$; IK95\% 1,4910,53), 2-7 hari $(\mathrm{RR}=6,11$; IK95\% 2,06-12,74) dan $>7-28$ hari $(\mathrm{RR}=5,59$; IK95\% 1,93-8,89).

\section{Pembahasan}

Proporsi BKB late preterm dari total 1468 kelahiran di RSUP Sanglah sebesar 6,67\% dan 71\% merupakan penyumbang terbesar kejadian kelahiran BKB. Data yang hampir serupa juga didapatkan di Amerika dan Kanada, dilaporkan pada tahun 1990, 10,5\% BKB late preterm dilahirkan dan meningkat menjadi $12,6 \%$ pada tahun 2005 dan hampir $75 \%$ BKB adalah late preterm. $^{2}$

Hasil penelitian kami konsisten dengan beberapa laporan penelitian pada populasi BKB late preterm, didapatkan peningkatan risiko kejadian kesakitan dan kematian pada bayi yang dilahirkan dengan usia kehamilan 34 minggu sampai dengan $<37$ minggu dibandingkan dengan $\mathrm{BCB}$ yang dilahirkan dengan usia kehamilan $>37$ minggu sampai 41 minggu. $^{4-12}$ Selain itu peningkatan risiko komplikasi selama masa perinatal juga dilaporkan pada beberapa penelitian, yang berimplikasi pada waktu yang lebih panjang untuk penanganan dan perawatan $\mathrm{BKB}$ late preterm dibandingkan BCB. ${ }^{13-16}$
Wang dkk, ${ }^{7}$ memeriksa dan membandingkan 90 $\mathrm{BKB}$ late preterm yang diambil secara random dan 95 $\mathrm{BCB}$, ditemukan peningkatan risiko pada $\mathrm{BKB}$ late preterm untuk kejadian respirasi distres, hipoglikemi, jaundice, ketidakstabilan suhu, dan sepsis. Hal tersebut sesuai dengan hasil temuan kami yaitu kejadian kesakitan yang tinggi pada BKB late preterm. Melamed $\mathrm{dkk}^{12}$ melaporkan peningkatan risiko respirasi distres, infeksi, hiperbilirubinemia, dan hipoglikemi pada BKB late preterm dibandingkan pada BCB.

Berdasarkan data dari populasi Khashu $\mathrm{dkk}^{5}$ melaporkan peningkatan risiko pada BKB late preterm untuk kejadian infeksi dan respirasi distress serta waktu yang lebih panjang untuk perawatan dirumah sakit dibandingkan pada BCB. Mulai tahun 1999 sampai dengan 2005, Pulver ${ }^{17}$ melaporkan hubungan kelahiran dan sertifikat kematian penduduk Utah, Amerika, didapatkan bahwa angka kematian yang tinggi pada $\mathrm{BKB}$ late preterm dibandingkan dengan $\mathrm{BCB}$.

Proporsi kelahiran BKB late preterm RSUP Sanglah Denpasar 6,67\%, yang merupakan 71\% dari total kelahiran BKB. Bayi kurang bulan (BKB) late preterm memiliki risiko lebih tinggi untuk menjalani waktu perawatan dirumah sakit, kejadian kesakitan. dan kematian dibandingkan BCB. Penelitian kami menggunakan subyek yang kecil serta waktu penelitian yang pendek, maka untuk mengetahui risiko BKB late preterm dipopulasi perlu penelitian dengan menggunakan subyek yang lebih besar dan waktu yang lebih panjang. 


\section{Daftar pustaka}

1. Lawn J, Shibuya K, Stein C. No cry at birth: global estimates of intrapartum stillbirths and neonatal deaths. Bull World Health Organization 2005; 83:409-17.

2. Davidoff MJ, Dias T, Damus K. Changes in the gestational age distribution among U.S. singleton births: impact on rates of late preterm birth, 1992 to 2002. Semin Perinatol 2006;30:8-15.

3. Damanik MS, Indarso F, Harianto A, Etika.R Masalah perawatan pada bayi prematur. Pelatihan Perawatan Neonatologi, 8 Maret - 8 Mei 2004; 1-12.

4. Clapp DW. Developmental regulation of the immune system. Semin Perinatol 2006; 30:69-72.

5. Khashu M, Narayanan M, Bhargava S, Osiovich H. Perinatal outcomes associated with preterm birth at 33 to 36 weeks' gestation: a population-based cohort study. Pediatrics 2009;123:109-13.

6. Escobar GJ, Clark RH, Greene JD. Short-term outcomes of infants born at 35 and 36 weeks gestation: we need to ask more questions. Semin Perinatol 2006;30:28-33.

7. Wang ML, Dorer DJ, Fleming MP, Catlin EA. Clinical outcomes of near-term infants. Pediatrics 2004;1 14:372-6.

8. Arnon S, Dolfin T, Litmanovitz I, Regev R, Bauer S, Fejgin M. Preterm labour at 34-36 weeks of gestation: should it be arrested? Paediatr Perinat Epidemiol 2001;15:252-6.

9. Sarici SU, Serdar MA, Korkmaz A, et al. Incidence, course, and prediction of hyperbilirubinemia in near- term and term newborns. Pediatrics 2004;113:775-80.

10. Seubert DE, Stetzer BP, Wolfe HM, Treadwell MC. Delivery of the marginally preterm infant: what are the minor morbidities? Am J Obstet Gynecol 1999;181:1087-91.

11. Bhutani VK, Johnson L. Kernicterus in late preterm infants cared for as term healthy infants. Semin Perinatol 2006;30:89-97.

12. Melamed N, Klinger G, Tenenbaum-Gavish K. Shortterm neonatal outcome in lowrisk, spontaneous, singleton, late preterm deliveries. Obstet Gynecol 2009; 114:253-60.

13. Shapiro-Mendoza CK, Tomashek KM, Kotelchuck M, Barfield W, Weiss J, Evans S. Risk factors for neonatal morbidity and mortality among "healthy," late preterm newborns.Semin Perinatol 2006;30:54-60.

14. Tomashek KM, Shapiro-Mendoza CK, Weiss J. Early discharge among late preterm and term newborns and risk of neonatal morbidity. Semin Perinatol 2006;30:61-8.

15. Kramer MS, Demissie K, Yang H, Platt RW,Sauve R, Liston R. The contribution of mildand moderate preterm birth to infant mortality. JAMA 2000;284:843-9.

16. Tomashek KM, Shapiro-Mendoza CK, Davidoff MJ, Petrini JR. Differences in mortality between late-preterm and term singleton infants in the United States, 19952002.J Pediatr 2007;151:450-6.

17. Pulver, L. S., Guest-Warnick, G., Stoddard, G. J., Byington. Weight for gestational age affects the mortality of late preterm infants. Pediatrics 2009;23:1072-7. 